Motrivivência Ano XXV, No 40, P. 51-66 Jun./2013

http://dx.doi.org/10.5007/2175-8042.2013v25n40p51

\title{
"COMO SABER SE MEU MUNDO DE IDEIAS DARIA CERTO NA PRÁTICA?" o medo da docência no estágio supervisionado em Educação Física
}

\author{
Luis Martiny? \\ Irani Souza ${ }^{2}$ \\ Pierre Gomes-da-Silva ${ }^{3}$
}

\section{RESUMO}

O objetivo desta investigação foi reconhecer as implicações dos medos vivenciados pelos futuros-professores nas suas práticas pedagógicas. Foram aplicados três questionários com perguntas estruturadas para 48 futuros-professores do curso de Educação Física da UFPB. Utilizando-se das técnicas de análise de conteúdo de Bardin (2008), foram mapeadas três categorias temáticas: a) prática de ensino e docência; b) dificuldades da docência e, c) formas de superação dos medos. O medo aparece como uma emoção essencial na ação dos futuros- professores. Pelo fato de o sentirem, são instigados a buscar mais conhecimento para desempenhar a sua prática docente e a refletir sobre a intervenção.

Palavras-chave: Medo; Docência; Estágio Supervisionado.

1 Mestre em Educação Física. Instituto Federal do Rio Grande do Norte. Natal/Rio Grande do Norte, Brasil. E-mail: luis_martiny@hotmail.com.

2 Graduada em Educação Física. Universidade Federal da Paraíba. João Pessoa/Paraíba, Brasil. E-mail: irani-edfisica@hotmail.com.

3 Professor Associado do Departamento de Educação Física Universidade Federal da Paraíba. João Pessoa/Paraíba, Brasil. E-mail: pierrenormandogomesdasilva@gmail.com. 


\section{INTRODUÇÃO}

O ser humano é dotado de uma infinidade de emoções, as quais possuem um papel fundamental no decorrer da sua vida existencial. Esses sentimentos influenciam-nos significativamente em muitos momentos do nosso agir humano. Isso acontece no ambiente do trabalho, em casa, na realização de tarefas recreativas, domésticas ou de labor. Uma destas situações em que afloram variadas cargas afetivas é no momento da atuação do professor em sala de aula.

Esse contexto de ensino-aprendizagem, repleto de pluralidade de pensamentos, em que as ideias são manifestadas, onde se evocam constantemente os contrastes, as resistências e as divergências de todos os atores sociais envolvidos, é que faz com que o professor tenha que lidar com inúmeras sensações distintas acerca do seu atuar docente. Essas sensações se estabelecem para além dos conteúdos a serem dialogados e contextualizados no interior da sala de aula. Estabelecem-se, principalmente, relações de troca entre alunos e professores.

As diferentes alterações energéticas acarretam comportamentos divergentes na ação do professor. Muitas dessas emoções começamantes mesmo do início da aula. No planejamento pedagógico, no plano de aula, na escolha do método, na didática, ali já são incorporadas uma gama de emoções comportamentais que acabam caminhando junto com trabalho do professor. Estas diferentes excitações transitam deste a ansiedade e o entusiasmo para com que a aula seja realizada com sucesso, até o medo de enfrentar a docência, de encarar a turma em que deverá ministrar sua aula. Isto tudo acontece, na maioria das vezes, antes mesmo do seu confronto real.
Os professores visualizam o impacto da sua atuação antes mesmo da sua vivência concreta. O docente idealiza os comportamentos dos alunos, suas angústias, aflições, e os tipos de enfrentamentos que terá que administrar e se submeter. Ao hipotetizar tais ações, ele (in)conscientemente modifica o seu atuar docente e subjulga os seus alunos e a sua intervenção como professor.

Um desses contextos em que se enfrenta(m) este(s) tipo(s) de situação-problema são os estágios supervisionados. Essas práticas de ensino se convertem em vivências responsáveis por levar o futuro-professor a construir articulações entre as diferentes disciplinas do curso de formação superior (licenciatura) e a sua prática docente concreta. Estes estágios acabam servindo como um canal de ligação entre os conhecimentos teóricos apreendidos na formação inicial e as experiências práticas vivenciadas no âmbito escolar. Essas atividades didáticas terminam por marcar um excelente elo entre a universidade e as escolas, visto que, é por meio delas que os futuros-professores começam a interagir com os contextos reais de aplicação da sua formação.

No mesmo instante em que esses estágios balizam um momento histórico no percurso acadêmico-profissional em decorrência de deixarem a condição passiva de alunos do curso e passarem à condição de regentes de turma, professores responsáveis pelo ensino de conteúdos, assumindo todas as implicações do exercício concreto da prática docente, eles despertam nestes futuros-professores singulares inquietações acerca da sua intervenção em um contexto escolar autêntico. Estas excitações envolvem, principalmente nesse primeiro contato com a docência, todo o agir dos futuros-professores. Para a grande maioria 
dos alunos do curso de formação superior, os estágios supervisionados se convertem no primeiro contato real com a docência.

Nesse sentido, esta pesquisa teve como objetivo primordial, identificar os diferentes tipos de medos vivenciados pelos alunos (futuros-professores) do $5^{\circ}$ e $6^{\circ}$ períodos do curso de Educação Física antes e durante o estágio supervisionado. Para tanto, buscou-se reconhecer quais foram as implicações de diferentes medos no desempenho docente. Por fim, procurou-se conhecer como esses futuros-professores fizeram para assumir e enfrentar esses medos. O que, de certa forma, nos possibilitou compreender porque eles sentem medo em assumir a docência supervisionada.

\section{METODOLOGIA}

Esta pesquisa é de natureza descritiva de abordagem qualitativa visto que se objetou analisar os medos da docência vividos por um grupo de alunos do curso de Educação Física, partindo da descrição daquilo que se mostra a partir de si mesmo, das expressões, posturas e relações faladas pelos próprios estagiários (MOREIRA, 2002).

A pesquisa teve como sujeitos os acadêmicos do curso de Educação Física da Universidade Federal da Paraíba, que estavam cursando o $5^{\circ}$ e $6^{\circ}$ períodos do ano letivo de 2008.1 a 2008.2, devidamente matriculados na disciplina Prática de Ensino que funciona sob a forma de estágio supervisionado. Participaram da pesquisa 48 futuros-professores. O quinto período era composto por 20 alunos, dos quais 11 eram do sexo feminino e 09 do sexo masculino. Em relação aos alunos do $6^{\circ}$ período, o grupo era constituído por 28 alunos, sendo 16 deles do sexo feminino e 12 do sexo masculino.

Para a coleta de dados, foram utilizados três diferentes questionários, que foram elaborados de acordo com os objetivos da pesquisa. O primeiro questionário foi aplicado aos alunos do $5^{\circ}$ e $6^{\circ}$ período, respectivamente, e foi composto de sete (07) questões abertas. Estas questões tinham os seguintes temas geradores: a) respeito às expectativas dos futuros-professores em relação à disciplina prática de Ensino em Educação Física; b) as experiências docentes anteriores; c) receios e medos relacionados à disciplina; d) experiências de fracasso e e) possível superação desses medos.

O segundo questionário, foi utilizado no inicio do período letivo e continha doze (12) questões direcionadas aos seguintes temas geradores: a) medo em relação à docência; b) segurança na adoção das abordagens pedagógicas vistas nessa disciplina; c) medos vivenciados durante a trajetória de vida e d) os medos relacionados com área de aprofundamento e sua forma de vencê-los.

O terceiro e último questionário foi composto por duas questões abertas e foi aplicado aos alunos do $6^{\circ}$ período. Esse questionário foi aplicado ao final da experiência docente na disciplina Prática de Ensino em Educação Física. As questões estavam relacionadas aos seguintes temas: a) medos superados e a permanência ou não do medo da docência e b) a forma como foram trabalhadas estas emoções.

Para conseguir obter os dados referentes ao $5^{\circ}$ período, a aplicação do primeiro questionário foi realizada no horário da aula da disciplina da graduação. Em contrapartida, o segundo questionário, direcionado ao grupo de alunos do $6^{\circ}$ período, 
foi aplicado em dois momentos: no primeiro momento a aplicação do questionário foi realizada no contexto de intervenção dos futuros-professores, ou seja, quando estes realizavam as aulas nas escolas. Já o segundo momento foi durante as aulas da prática de ensino na Universidade.

O terceiro questionário foi realizado ao final da disciplina, no momento em que os futuros-professores pesquisados iriam apresentar os resultados dos seus respectivos estágios supervisionados. Todos os futuros-professores pesquisados responderam os questionários antes e depois da intervenção.

Após a realização dos 144 questionários que foram aplicados, as informações recolhidas foram divididas em categorias semelhantes, para realização da análise e interpretação das informações alcançadas. A técnica utilizada foi a de analise de conteúdo de Bardin (2008).

As respostas foram sendo agrupadas de acordo com a semelhança entre elas e, a partir de então, as categorias de análise foram sendo construídas. A partir dessas informações, por meio desses procedimentos, foram feitas as constatações e a confrontação dos resultados com a literatura.
Das análises interpretativas realizadas a partir dos três diferentes questionários aplicados nos 48 futuros-professores investigados, foram identificadas três grandes categorias temáticas relacionados à prática de ensino e ao medo da docência. Essas categorias foram assim aproximadas: a) Prática de ensino e a docência; b) as dificuldades da docência e c) forma da superação dos medos. Tais categorias nos possibilitaram a identificação e as implicações desses medos na atuação dos futuros-professores em relação às práticas de ensino. A pesquisa foi aprovada pelo comitê de ética e pesquisa da UFPB sob o número 0264.

\section{RESULTADOS E DISCUSSÃO}

A partir das análises realizadas foram encontradas, por meio das respostas aos questionários, três grandes categorias temáticas. No interior de tais categorias encontradas, manifestaram-se algumas subcategorias. Essas categorias e subcategorias abordam os medos docentes provenientes da intervenção pedagógica e que foram manifestados no atuar dos futuros-professores. O quadro 1 a seguir mostra estas categorias e subcategorias.

Quadro 1 - Categorias e subcategorias temáticas em relação ao medo da docência no estágio supervisionado

\begin{tabular}{|l|l|}
\hline Categorias temáticas & Subcategorias temáticas \\
\hline \multirow{4}{*}{ Prática de ensino e medo da docência } & Expectativas em relação ao estágio; \\
\cline { 2 - 2 } & Receios sobre a intervenção; \\
\hline \multirow{5}{*}{ Dificuldades da docência } & Falta de experiência; \\
\cline { 2 - 2 } & Fatores que influenciam os medos; \\
\cline { 2 - 2 } & (Des)preparo para a docência; \\
\cline { 2 - 2 } & $\begin{array}{l}\text { A pesquisa como elemento para minimizar o medo } \\
\text { da docência; }\end{array}$ \\
\cline { 2 - 2 } & Implicações; \\
\hline Superação dos medos & Enfrentamento com a realidade; \\
\hline
\end{tabular}


A primeira dessas categorias está relacionada à prática de ensino e o medo da docência dos futuros-professores. Dessa categoria surgiu a primeira subcategoria temática, que ficou atrelada às expectativa dos alunos em relação à disciplina curricular "prática de ensino em Educação Física" (GOMES-DA-SILVA, 2009).

Sobre essa primeira subcategoria, as resposta dos futuros-professores tanto do $5^{\circ}$ como do $6^{\circ}$ período foram semelhantes. De acordo com os retornos obtidos sobre a expectativa deles para com a disciplina, percebeu-se que a disciplina atende as expectativas dos alunos. Fato que claramente pode ser observado na resposta da grande maioria dos acadêmicos investigados. Eles mesmos disseram que esta disciplina é de extrema importância, pois é por meio dela que podem vivenciar uma experiência real da prática docente, podendo dessa forma, por em prática os conteúdos aprendidos anteriormente nas disciplinas curriculares oferecidas ao longo do curso.

Após a análise dos questionários, observou-se que a maioria dos acadêmicos relata que o estágio é uma grande oportunidade para se autoavaliarem e decidam qual área de aprofundamento seguir. Outra resposta importante muito frequente foi em relação à competência do coordenador da disciplina, que é admirado por muitos.

[...] Para mim ele é um profissional completo e um modelo a ser seguido. É de uma tamanha sensibilidade e dedicação, demonstrando que faz seu trabalho com amor [...] sempre estava disposto a nos ensinar e paciente com nossas inseguranças. Sempre nos motivando a ter coragem e persistência, (Futuro-Professor $10-6^{\circ}$ período).
Estas expectativas criadas acerca do estágio criam um ambiente que os auxilia a regular o medo. Esse ambiente controlado, ou seja, de menor incerteza, regulado por meio das expectativas, pode ajudar os futuros-professores a tomar decisões mais consistentes acerca da docência, das tarefas didáticas e comportamentos pedagógicos. Visto que, segundo Bauman (2008), o medo é um importante modelador de comportamento. Em uma primeira instância, ele vem reformar a percepção de mundo do indivíduo e consequentemente, guiar suas expectativas de comportamento. Para o autor, o medo afeta as nossas escolhas e decisões ao longo de sua vida, e nesse caso, especificamente, a vida acadêmica dos futuros-professores (BAUMAN, 2008).

De acordo com o relato de 6 futuros-professores, pode-se observar a insatisfação em relação a carga horária disponível para esta disciplina. Os futuros-professores acreditam não ser suficiente para o aprendizado de tantas informações que são transmitidas nesse momento. Eles acreditam que deveriam permanecer e aprender mais em sala de aula antes de enfrentar a vida docente.

A partir de tais inquietações, surgiu uma segunda subcategoria temática que diz respeito aos receios dos futuros-professores em relação à disciplina. Para os futuros-professores do $5^{\circ}$ período, os maiores receios relatados estavam centrados no preparo para assumir a docência. Essa manifestação decorreu em virtude de se sentirem ainda despreparados no momento em que precisam atuar como docentes. Houve relatos quanto a não conseguir atender as expectativas do coordenador da disciplina Prática de Ensino. 
No começo da disciplina o maior receio era o de não conseguir atender as exigências da disciplina e as expectativas que o professor colocou sobre nós (Futuro-Professor $11-6^{\circ}$ semestre).

Já em relação aos dois questionários aplicados no $6^{\circ}$ período, os futuros-professores investigados responderam que o receio maior estava em não conseguir concluir todas as etapas da disciplina, visto que eles acreditavam que a disciplina era muito trabaIhosa e extensa. Além disso, eles acabaram apresentando outras duas ansiedades que incidiram sobre a falta de experiência na docência e nas possíveis dificuldades que iriam encontrar na escola e, mais especificamente, no interior da sala de aula.

Nesse sentido, os futuros-professores de ambos os períodos sentiam muito receio de assumir a docência por não terem vivenciado experiências docentes anteriores. O que, de certa forma, acarretou em certo medo para com a disciplina. Para Koury (2002) o medo é uma construção social significativa, porque faz parte do processo de sociabilidade. Ao concordar com esta informação se acredita que a disciplina, pelo fato de evocar diversas emoções, acaba por ser um momento muito importante para a vida e carreira destes futuros-professores. haja vista o medo ser um importante modelador de comportamentos.

Os principais medos dos futuros-professores, tanto do $5^{\circ}$ quanto do $6^{\circ}$ período, para com a disciplina foi em relação à falta de domínio nas abordagens pedagógicas estudadas. Estas abordagens são apresentadas para os futuros-professores durante a realização do $5^{\circ}$ período. Ao total são apresentadas três diferentes abordagens pedagógicas, assim sistematizadas : Corpo Inteiro (FREIRE; SCLAGLIA, 2003),
Desenvolvimentista (GALLAHUE; OZMUN, 2001) e Crítico Superadora (COLETIVO DE AUTORES, 1993), que são utilizadas pelos futuros-professores no $6^{\circ}$ período do curso.

Os futuros-professores, ao ingressarem neste $6^{\circ}$ período, se deslocam para escolas da rede pública de ensino de João Pessoa-PB e escolhem uma dessas abordagens para ministrarem suas aulas. No total, cada um dos futuros-professores necessita ministrar no mínimo 24 aulas durante o estágio. Normalmente a intervenção dos futuros-professores na escola tem duração de três meses. Nesse período os futuros-professores realizam as intervenções com uma frequência de três vezes na semana, com uma hora aula por encontro. Desse total de aulas, é exigida dos futuros professores, a realização de no mínimo duas unidades programáticas (cf. ementa do componente curricular)

Nota-se, portanto, nesse momento de intervenção, que os medos dos futuros-professores, possivelmente são atribuídos à falta de conhecimento das propostas. Eles ficam indecisos com relação à escolha da abordagem ideal para determinada turma. Esta indecisão gera uma insegurança que vai se refletir no agir do futuros-professores em sala de aula.

Um segundo fato relatado foi relacionado à "pressão" que estes futuros-professores sentem ao deparar com o estágio. Isso acontece, em virtude de que, no momento da intervenção na escola, além de não possuírem experiência na docência, são atribuídas a eles diversas funções, tais como: apresentarem plano de aula e de ensino, ministrarem as aulas-laboratórios, que são supervisionadas; construírem um vídeo para ser apresentado para toda turma; participarem de encontros pedagógicos com 
os supervisores e coordenador da disciplina e construírem o relatório final.

Outro fato observado foi que os futuros-professores remetem seu medo ao fato de estarem sendo avaliados e observados constantemente, por seus supervisores o que os deixa muito incomodados, possivelmente, devido a estarem sendo avaliados em seus planos de aula, como também na execução de suas aulas propriamente ditas.

Contudo, não se pode considerar o medo da disciplina como algo ruim, pois, segundo Almeida (1999), o medo é uma emoção básica e que pode atuar de forma positiva sobre o desempenho intelectual dos acadêmicos, dependendo da intensidade. $\mathrm{O}$ medo pode vir a oferecer possibilidades ao produzir desafios, sem os quais não haveria progresso da inteligência.

A necessidade de produção de desafios evidencia a segunda categoria temática, que diz respeito às dificuldades da docência. Dessas dificuldades decorre uma primeira subcategoria temática reconhecida acerca dos principais medos para assumir a docência.

Pode-se observar que o medo ocorre devido à pouca experiência na docência, mas mais especificamente, com o fato de os futuros-professores depararem com a hipótese de assumir uma turma de crianças numa determinada escola. Os alunos sentem medo de realizar determinadas atividades específicas de um professor em sala de aula.

Para Almeida (1999) ocorre uma relação particular entre o medo e as reações de equilíbrio do indivíduo, já que o medo é despertado quando ocorre uma ameaça a esse equilíbrio, por meio do conflito. A ameaça está intimamente relacionada com a falta de experiência dos futuros-professores.
Já o fator conflitante estaria relacionado às atividades ou as responsabilidades que assumem naquele momento, com sua turma de alunos, com a escola, com o supervisor, com os colegas de grupo e com o coordenador. Fatores que possivelmente podem em muito gerar este desequilíbrio e, por conseguinte, despertar o medo nos futuros-professores.

Estes fatores amedrontadores podem ser observados no relato dos futuros-professores em seus relatórios finais. Os relatórios fazem referência às experiências vivenciadas durante o Estágio Supervisionado, no período de 2008.1.

[...] uma das maiores dificuldades encontradas, por mim estagiário, foi a falta de experiência em ministrar aulas na escola. Se os conteúdos abordados estão corretos, se eles estão condizentes com o plano de ensino, se a proposta pedagógica que está sendo trabalhada é a correta. (Futuro-Professor 1 - $6^{\circ}$ Período).

Devido ao fato de nunca ter lidado com crianças senti-me inseguro. A maior dificuldade encontrada foi em relação a como falar com elas no que diz respeito a conseguir a atenção delas. Faltava-me o embasamento teórico relativo às atividades a serem desenvolvidas com as crianças, fiquei triste e desesperado estava tão desanimado que cheguei ao ponto de chamar os colegas de estágio e supervisora, para dizer que ia desistir. (Futuro-Professor 3 - $6^{\circ}$ período).

Contudo, os conflitos vivenciados nesses momentos de formação inicial são de extrema importância para despertar os seus interesses e aprendizados. Para Monteiro e Gaspar (2007), por exemplo, essas reações emocionais expressadas pelo indivíduo, especialmente em meio a conflitos, atuam substancialmente sobre formas do 
comportamento dos futuros-professores e do processo educativo.

Os outros medos advindos da falta de experiência na docência foram relacionados : a) ao fato de não saberem ensinar os conteúdos escolhidos em relação às propostas pedagógicas e: b) à condição de não saberem controlar um grupo de crianças. Pode-se perceber que inicialmente o fato de assumir uma turma e a escolha de uma determinada proposta pedagógica parece ser algo amedrontador para alguns dos futuros-professores, especificamente, pela sua falta de experiência. Mais uma vez os fatores citados acima podem ser visto inúmeras vezes em seus relatórios finais.

Defrontei-me primeiro com o medo. Como saber se meu mundo de ideias daria certo na prática? Até o momento as aulas eram apenas ideias formuladas na minha mente e escritas em papéis (Futuro-Professor 4 - $6^{\circ}$ período).

[...] fiquei com muito medo e apreensivo no primeiro momento do estágio, que foi o primeiro contato com a escola. Pois nunca em toda minha vida, tinha provado algo parecido com que estava prestes a acontecer. De inicio tive dificuldades, pois era uma área da Educação Física onde não existia interesse da minha parte e que por conta disso fiquei inseguro e cheguei a achar que não iria conseguir. (Futuro-Professor 6 - $6^{\circ}$ período).

As falas em si, revelam o quanto o medo esta relacionado às nossas escolhas pessoais. Quando pensamos no medo, nas distintas situações enfrentadas é que somos levados a refletir sobre a necessidade que temos de ser muito claros a respeito de nossas opções. Isso, por sua vez, exige que tenhamos certos tipos de procedimentos e práticas concretas (FREIRE, 1996). As próprias experiências relevam ou afloram os nossos medos sobre as situações vivenciadas.

As situações que ainda não adquirimos certo controle fazem com que tenhamos sensações novas em relação a como proceder para retomar o seu domínio. Disso decorre uma segunda subcategoria temática a qual esta focada sobre os fatores que influenciam esses medos.

Os futuros-professores atribuíram seus medos principalmente a fracassos ocorridos anteriormente em outras fases de sua vida. Por não conseguirem corresponder às expectativas que foram criadas sobre eles, possivelmente esses acontecimentos os tornaram inseguros para assumir uma prática docente. Medos vividos anteriormente podem ser despertados quando as pessoas são instigadas a viverem situações iguais ou semelhantes àquelas vivenciadas em sua história de vida.

Outro fator observado foi que, seus medos tinham sido influenciados por comentários que outros profissionais faziam a respeito do comportamento de crianças de baixa renda e também, pela divulgação na mídia a respeito de acontecimentos em escolas da periferia. Ese fator provoca o comentário feito por Murray (1973), quando diz que as emoções são poderosas reações que exercem efeitos motivadores sobre o comportamento. Elas provocam reações fisiológicas e psicológicas que influenciam na percepção, aprendizagem e desempenho.

Percebe-se, dessa forma, a importância e interferência das emoções na vida dos seres humanos. São elas que ocasionam diversas mudanças diretas, não somente na vida em sociedade, como também nas escoIhas pessoais de cada ator social. $\mathrm{O}$ único fator que vem a diferenciar uma emoção 
de outra é a intensidade com a qual ela é vivida nos indivíduos, caracterizada pelo nível de ativação no organismo, que envolve e acompanha mudanças no corpo, nas expressões e, sequencialmente, nas ações (LAVOURA, 2008).

O envolvimento pessoal na relação direta com a tarefa a desempenhar passa a ser um dos reguladores das intensidades emotivas. Na complementaridade dessa troca, surge a terceira subcategoria temática dentro da categoria das dificuldades da docência. Os futuros-professores ao se confrontarem e envolverem-se com a tarefa educativa tendem a sentirem-se e julgarem-se (des)preparados para assumir a docência.

Segundo Dely (1999), o processo de criação do sentimento do medo, começa com um estímulo assustador demonstrado pelo receio de fazer alguma coisa, quando o indivíduo é posto em situações novas e inesperadas. Esse indivíduo se sente ameaçado tanto fisicamente quanto psicologicamente, demonstrando uma reação de luta ou fuga. Ao se pormenorizarem, os futuros-professores, iniciam o processo de criação do sentimento de medo em relação ao estágio e à docência.

Dessa forma, pode-se observar que é necessário um estímulo para que o medo possa ser despertado. Nesse caso, o estímulo que é percebido como assustador é o fato dos futuros-professores deixarem a posição de alunos e passarem naquele momento a serem professores, assumindo responsabilidades e restrições, típicas da profissão docente.

De acordo com os dados obtidos, os poucos futuros-professores que alegaram estar preparados para assumir a docência, apegaram-se ao fato de já atuarem em projetos de extensão da própria Universidade.
São projetos que envolvem trabalhos com crianças e que os colocam em situações reais de docência. Isso, de certa forma, tornou-os mais seguros em relação à transição de aluno a professor.

Já os alunos que relataram não estarem preparados para esse momento de transição, alegaram ser por falta de experiência. Dessa forma, pode-se perceber que há no curso de Educação Física da UFPB poucas atividades concretas de docência, visto que, a maioria dos alunos não se sentem preparados para enfrentar as situações de ensino-aprendizagem, com exceção daqueles que possuem experiências na extensão ou em experiências docentes anteriores.

Partindo disto, faculta-se pontuar que as atividades acadêmicas limitam-se a exposições teóricas e esse fato pode estar prejudicando os alunos no que diz respeito à docência. Nessa dimensão, as disciplinas no currículo que tratam com a educação física escolar podem não estar ajudando a saberem lidar com crianças e os processos de aprendizagem.

Para os futuros-professores, faz-se pertinente haver mais momentos práticos no currículo do curso. Eles declaram que nenhuma teoria é a mesma quando aplicada na prática e que os conteúdos teóricos desenvolvidos nos semestres anteriores ao $6^{\circ}$ período deixaram muito a desejar em termos de aproximação com a realidade escolar. Diante das suas dificuldades um dos futuros-professores faz o seguinte desabafo em seu relatório final:

A amizade entre os participantes do grupo foi bastante forte, principalmente nas horas de dificuldades. A bagagem teórica até o sexto período é muito fraca, podendo ser considerada pobre, não só por culpa dos professores, mas 
principalmente pelo desinteresse dos alunos (Futuro-Professor 8 - $6^{\circ}$ período).

Maturana (2002) considera a juventude como uma etapa importantíssima na história dos indivíduos, pois ela traz consequências fundamentais para o tipo de sociedade que os mesmos trazem em seu viver. Por isso, prevendo as possibilidades de mudança social, em termos de educação física escolar, que podem ser desencadeadas pelos jovens, apontamos para uma mudança curricular que atente para essas lacunas teóricas epráticas do currículo atual, em relação ao exercício docente.

Muitos autores, dentre os quais Borges (1998), Bracht et al (2003) e Fuzi et al (2009) têm apontado esse distanciamento entre a formação e a intervenção. Esse possível afastamento entre estes dois contextos faz com que os futuros professores acabem por julgar incipiente a sua formação inicial. Nesse dizer, eles se voltam às disciplinas do curso para caracterizá-las como elementares em relação aos problemas vividos quando no contexto real de intervenção.

Os futuros professores, ao não conseguirem encontrar soluções para as situações-problema nas próprias disciplinas da formação, recorrem a utilização de outros meios para vencer os medos da docência. Essa passa a ser uma quarta subcategoria que aparece em relação às dificuldades da docência.

Segundo os futuros-professores um dos meios utilizados para superar esses medos foi a familiarização com os conteúdos teóricos, por meio da leitura de livros e artigos, que pudessem auxiliar no desafio vivido. O que pode ser observado é que quando ocorrem desafios, os alunos são instigados ao aprendizado que, por sua vez, geram novos conhecimentos, mas que permitem diminuir, dessa forma, o nervosismo em relação à docência. De acordo com Golemam (2001), o nervosismo é um aspecto secundário gerado pelo medo, que nesse caso é o medo de assumir a docência.

Medo é o nome que se dá à incerteza, à ignorância do que se deve, do que se pode ou do que não se pode ser feito, que termina por nos ameaçar. E que para fazê-la parar ou enfrentá-la está além do nosso alcance (BAUMAN, 2008).

Pode-se perceber que à medida que os futuros-professores iam sendo instigados a pesquisar sobre conteúdos aliados à prática, os mesmos conseguiam vencer ou, ao menos, minimizar seus medos. O que nos reporta a ideia da necessidade de desafiar a inteligência para que ela possa se desenvolver com melhor êxito. Para Almeida (1999), por exemplo, a emoção instiga a inteligência toda vez que a ameaça com sua insubordinada presença na atividade do conhecimento. A inteligência, por sua vez, necessita das tormentas do medo para ser estimulada a se desenvolver. $\mathrm{O}$ medo impõe à inteligência o desafio de superá-la, instigando-a ao uso de todas as habilidades e capacidades lógicas do indivíduo.

Outro ponto de destaque é a pertinência da leitura como meio utilizado para a superação desses medos. Voltar-se aos livros para encontrar neles possíveis respostas às inquietações que a prática educativa provoca. A utilização deles surge como um aporte seguro, que transita desde a simples eleição de uma tarefa a ser realizada em aula até a adequada verificação acerca da fundamentação teórica elegida. Tudo isto para confrontar com os desafios, que de acordo com os relatos apresentados nos questionários, são impostos pelo Estágio Supervisionado. 
Por fim, disso decorre a quinta subcategoria das dificuldades da docência. Surgem aqui as implicações dos medos na docência. Neste sentido, o Estágio Supervisionado torna-se um desafio a ser ultrapassado e vivido pelos futuros-professores.

O estágio é uma experiência vivida de muita tensão e nervosismo, que resulta em crescimento cognitivo, emocional e profissional. Essa vivência ganha valor quando o sistema educacional torna-se a configuração de um mundo, e o que resta aos educandos é confirmarem em seu dia-a-dia o mundo em que viveram em sua educação (MATURANA (2002).

O medo, nesse estudo, é considerado como uma emoção primordial e essencial, pois, é em virtude do fato de o sentirem, que os futuros-professores são instigados a buscar mais conhecimento da prática docente, visto que, as emoções são concebidas como uma motivação para cognição e para o comportamento, ou seja, como uma sensação primordial ao desenvolvimento humano (TORRES; GUERRA, 2003).

Para finalizar, aparece uma terceira grande categoria temática interpretada na forma da superação dos medos da docência por parte dos futuros-professores. Esta categoria se aprofunda em uma subcategoria que diz respeito a possibilidades de vencer os medos da docência. Descrevem-se, nesse primeiro momento as suas possibilidades de supera-los.

O modo mais simples de vencer o medo é arriscando. Freire (1996) nos fala que se você não comanda seu medo, você deixa de arriscar, você não cria nada. Portanto, sem arriscar, não há possibilidade de existir. No transcorrer da formação inicial, como não é possível concluir o curso de licenciatura em Educação Física, sem passar pelo Estágio Supervisionado, os futuros-professores são convocados a arriscarem suas idéias, suas escolhas, seus conceitos, seus conhecimentos e suas capacidades.

Nesse convite ao risco um dos futuros-professores do $6^{\circ}$ período, que naquele momento lecionava na Creche-Escola, para crianças de 4 anos, escreveu uma frase que retrata bem o sentido de vencer o medo.

O medo de tentar é algo temporário, mas o arrependimento por não ter tentado é eterno (Futuro-Professor $3-6^{\circ}$ período).

O primeiro traço apresentado pelos futuros-professores para superação do medo foi o esforço, a dedicação. Eles relataram que foi com muita dedicação que conseguiram mergulhar, por necessidade urgente, no mundo dos livros, dos artigos e de outros meios para adquirir mais segurança no planejamento e na aplicação dos conteúdos.

Para eles, o medo surge por intermédio do desconhecido, visto que o ambiente escolar, para muitos deles, era um espaço totalmente inexplorado em seu dia-a-dia. E o desconhecido aliado à falta de prática, gera medo. Este medo é desencadeado sob a forma de: ansiedade, apreensão, nervosismo, preocupação, inquietação, insegurança, susto e, em alguns poucos, terror. Contudo, aliados à pesquisa e à dedicação, com o tempo, o medo passa e os futuros-professores vão tornando-se mais seguros para planejar e lecionar.

Outro fator de superação do medo que foi apresentado estava direcionado à coletividade. Especificamente o ponto destacado foi a cooperação, ou seja, o sistema de incentivo mútuo desenvolvido por parte dos integrantes do grupo, do coordenador e 
do supervisor. Pode-se perceber que o auxílio dos outros, o companheirismo, o não sentir-se só, é um fator fundamental para promover, além do aprendizado individual e grupal, a superação do medo. Há um comentário de um futuro-professor que deixa esse mecanismo de superação evidente.

O diálogo com meus colegas e com o professor Pardal foi de suma importância para a correção dos meus erros, bem como no auxílio na regência das aulas. A amizade entre os participantes do grupo foi bastante forte, principalmente nas horas de dificuldade. Sinto um alívio grande ao término do estágio, e também sinto saudades da minha turma e da escola como um todo. O estágio serviu como um divisor de águas, todos os medos e anseios foram enfrentados e superados, agora me sinto mais corajoso e competente para seguir adiante (Futuro-Professor $8-6^{\circ}$ período).

Aparece aqui a ideia defendida por Freire (1995) de que os professores não se fazem sós, nem devem fazer as suas ações só, mas sim necessitam fazer-se com os outros, e desses fazendo-se as intervenções. Evoca-se a importância do trabalho coletivo dos futuros- professores. Da pertinência da troca de experiências e aflições. Da acuidade de falarem sobre as suas experiências vividas e vivenciadas. De conseguirem dar voz às suas alegrias e inquietações.

Voz essa que deflagra outro ponto importante em relação ao medo da docência: o tempo do estágio. Com o desenrolar da prática de ensino os futuros-professores foram adquirindo segurança em relação à sua atuação docente. "Vi que a Prática de Ensino em Educação Física não é um bicho papão, como os outros diziam" (Futuro-Professor $18-6^{\circ}$ Período). Observou-se mais uma vez, que o medo só se instala nos futuros-professores porque no momento inicial, antes mesmo da realização da disciplina, ocorrem muitos comentários sobre o Estágio.

Como se trata de um campo de atuação desconhecido para a maioria dos futuros-professores, o medo, nessa dimensão, torna-se difuso. Para Bauman (2008), o medo é mais assustador quando difuso, disperso, indistinto, desvinculado, desancorado, flutuante, sem endereço nem motivo claros; quando nos assombra sem que haja uma explicação visível, quando a ameaça que devemos temer pode ser vislumbrada em toda parte, mas em lugar algum se pode vê-la.

$\mathrm{Na}$ medida em que os futuros-professores adquirem experiência com a prática e a pesquisa, eles começam a perceber que o estágio e, consequentemente, o ambiente escolar não são algo que se deva temer, mas é um excelente local de aprendizado recíproco. Nesse momento, eles terminam por reconhecer a riquíssima troca de conhecimentos que acontece nesta experiência docente e que a torna inesquecível.

Confesso que aprendi muito com a disciplina Prática de Ensino, antes mesmo de ter conhecimento da existência da disciplina, tinha certeza absoluta de que não queria e não iria escolher a área escolar e hoje, já se tornou uma opção de carreira. É da natureza do ser humano temer o desconhecido, pois nunca em toda minha vida, tinha provado algo parecido com que estava prestes a acontecer. De início tive dificuldades, pois era uma área da Educação Física onde não existia interesse da minha parte e que por conta disso fiquei inseguro e cheguei a achar que não iria conseguir. Mal sabia eu que estava enganado. (Futuro-Professor $6-6^{\circ}$ período). 
De acordo com Monteiro e Gaspar (2007) não é possível ocorrer aprendizado sem emoção. É indispensável não utilizar a emoção como elemento auxiliador da docência, pois esta não é apenas uma atitude aceitável, mas também desejável. As reações emocionais expressas pelos futuros professores, especialmente em meio a conflitos, atuam substancialmente sobre formas do comportamento em processo educativo.

É acerca dessas dinâmicas configurações do agir do professor e do aluno que o medo da docência ainda permanece. "O medo caminha lado a lado com o desconhecido e cada aula é um novo desafio, com novas superações" (Futuro-Professor $3-6^{\circ}$ período). Para os futuros professores, apesar de terem conseguido superar esses medos, eles acreditam que ao trabalhar com outras faixas etárias, seria outro grande desafio e novamente sentiriam aquele "frio na barriga", como manifestação de medo e insegurança. Como se pode presenciar o medo surge a partir de um estímulo considerado desconhecido e esse estímulo pode ser referente a experiências vividas anteriormente por eles.

De acordo com Baptista, Carvalho e Lory (2000), os medos aparecem quando são úteis, como a ansiedade de separação, o medo das alturas ou a ansiedade social, e desaparecem, habitualmente, quando essas tarefas estão suficientemente dominadas e deixam de construir ameaça. Dessa forma, pode-se observar que apesar da rica experiência do Estágio, qualquer outra experiência que seja totalmente nova para os futuros-professores, novamente irá despertar essa emoção. Os medos aparecem e desaparecem, de modo previsível, em determinadas alturas do desenvolvimento, de acordo com as tarefas típicas dessa etapa. Essa transitoriedade e reaparecimento do medo também podem ser vistos nos estudos de Baptista, Carvalho e Lory (2000; 2008).

Por fim, destaca-se ainda a representação que foi para os futuros-professores terem superado esse medo da docência. Para alguns, essa vitoria representou a superação de limites, pois foi através do Estágio que puderam perceber que a prática docente não é algo à parte da vida acadêmica e que esse é um excelente momento para aprender mais. Koury (2002) afirma que o medo é uma construção social significativa, porque ela reconfigura o processo de sociabilidade.

Em meio aos conflitos de conhecimento vivenciados na disciplina, os futuros-professores aprimoraram sua busca investigativa, acrescentando outros conhecimentos. Entretanto, isso só acorreu por meio de vivências práticas. Por isso eles iniciam por evocar aqui a importância da prática docente como essencial e indispensável para um aprendizado mais completo. Dessa forma eles sinalizam a sua maior presença no currículo do curso de educação física.

O estágio foi extremamente produtivo por poder proporcionar a todos os alunos de Educação Física a vivência da realidade escolar. Encontramos na escola uma realidade que ia além das teorias tão discutidas em sala de aula. (Futuro-Professor 4 - $6^{\circ}$ período).

\section{CONSIDERAÇÕES FINAIS}

A disciplina Prática de Ensino em Educação Física/Estágio Supervisionado é considerada como uma atividade essencial, porque favorece o desenvolvimento e aperfeiçoamento do aprendizado intelectual, oportunizando aos acadêmicos do curso de Educação Física uma percepção maior ao 
seu papel enquanto professor. O Estágio Supervisionado assume atualmente um papel de fundamental importância por oferecer experiências pedagógicas concretas, no âmbito escolar, para que os futuros-professores possam assumir sua função docente.

Com respeito aos principais medos de assumir a docência, os futuros-professores relacionaram tais emoções com a falta de experiência docente. Esta evidência denota em um primeiro momento a singularidade da ação docente do professor. Já em um segundo momento isso comprova a dificuldade da docência no âmbito escolar. Estas ocorrências se justificam em virtude de muitos dos futuros-professores já terem realizando trabalhos secundários semelhantes ao trabalho de professor, antes do estágio, mas que não foram suficientes para inibir o medo que sentiram em relação à prática docente. $\mathrm{O}$ contexto dinâmico da sala de aula caracteriza a necessidade de constante adaptação e presença do novo, do inacabado, do desconhecido. Então os futuros-professores ao realizar e assumir determinadas funções e posturas típicas de um professor, necessitam de um constante ajustamento das suas obrigações ao ambiente dinâmico e plural que estarão realizando a sua intervenção.

Com relação às implicações que os medos podem causar nos futuros-docentes pode-se notar que ele exerce uma função positiva, no que diz respeito à construção de um melhor aprendizado e desenvolvimento intelectual. O medo, emoção motivada pela falta de experiência na docência, faz com que os futuros-professores (re) visitem as fontes bibliográficas, faz ainda com que eles busquem, em livros ou outras fontes documentais, respostas para os seus problemas que os permitam controlar ou ao menos minimizar as suas diferentes emoções. $\mathrm{O}$ medo foi vencido à medida que eles foram sendo instigados a pesquisar sobre os conteúdos da atividade dos professores aliando-os à sua prática docente autêntica. Estas experiências reais provocaram o desenvolvimento de suas inteligências pedagógicas.

Outro ponto a destacar é que não houve casos, nos dois semestres avaliados, que o medo produziu ostracismo nos futuros-professores. Nenhum dos 48 futuros-professores entrevistados abandonou a prática de ensino ou se recusou a ministrar aulas nas escolas em virtude do medo gerado. O que de fato aconteceu seguiu a ordem inversa ao abandono da prática. Percebeu-se sim, que os futuros-professores que aparentaram este medo inicial em relação à sua primeira intervenção docente acabaram se dedicando mais em relação à sua atuação em comparação aos futuros-professores que já haviam vivenciado experiências docentes antes da prática de ensino.

\section{REFERÊNCIAS}

ALMEIDA, A. Emoção na sala de aula. Campinas, SP: Papirus, 1999. BARDIN, L. Análise de Conteúdo. 8. ed. Lisboa: Edição 70, 2008.

BAUMAN, Z. O Medo Liquido. Rio de Janeiro. Jorge Zahar, 2008.

BAPTISTA, A; CARVALHO, M; LORY, F. Aprender a lidar com as dificuldades emocionais. $O$ centro de aconselhamento para estudantes. Revista de Humanidades e Tecnologias, 4/5, 227-237. 2000.

BAPTISTA. A; CARVALHO. M; LORY.F. O medo, a Ansiedade e as suas Perturbações. Disponível em: < http://cae.ulusofona.pt/artigos/ psicol $\% 20$ barata $\% 20$ art.pdf $>$. Acessado em: 09 de novembro de 2012. 
BORGES, C. O professor de educação física e a construção do Saber. São Paulo: Papirus, 1998.

BRACHT, V. (org); Pesquisa em ação: educação física na escola. ljuí: Unijuí, 2003.

COLETIVO DE AUTORES. Metodologia do Ensino de Educação Física. São Paulo: Cortez, 1992.

DELY. P. Aprenda a lidar com suas Próprias Emoções. Portal Educacional: A internet na Educação. Disponível em: www. educacional.com.br.Acessado em: 26 de outubro.2012.

FREIRE, J.; SCAGLIA, A. Educação como prática corporal. São Paulo: Scipione, 2003.

FREIRE, P. Pedagogia da autonomia. $23 \mathrm{ed}$. São Paulo: Paz e terra, 1996.

FUZI, F. et al. Teoria da Formação e Avaliação no Currículo de Educação Física. Motriz, Rio Claro, v. 15 n. 1 p. 13-24, jan./ mar. 2009.

GALLAHUE, D; OZMUN，J. Compreendendo o desenvolvimento motor: Bebês, Crianças, Adolescentes e Adultos. São Paulo: Phorte, 2001.

GOMES-DA-SILVA, P. Prática de ensino em educação física: por uma formação do professor-pesquisador. In: HERMIDA, J.F
(Org.). Educação Física: Conhecimento e saber escolar. João Pessoa, Paraíba: UFPB, 2009. p.103-128.

KOURY, M. Medos Corriqueiros: Em Busca de uma Aproximação Metodológica. Conceitos.N8, RP 120 a 126, JunhoDezembro,2002.

LAVOURA, T. Medo no Esporte: Estados emocionais e Rendimento Esportivo. Jundiaí, SP: Fontoura, 2008.

MATURANA, H. Emoções e linguagem na educação e na política. Belo Horizonte: Ed. UFMG, 2002.

MONTEIRO, I.; GASPAR, A. Um estudo sobre as emoções no contexto das interações sociais em sala de aula. Investigações em Ensino de Ciências, v. 12, p. 1, 2007.

MOREIRA, V. Psicopatologia Crítica. In: MOREIRA, V; SLOAN, T. Personalidade, Ideologia e Psicopatologia Crítica. São Paulo: Escuta, 2002.

MURRAY, E. Motivação e Emoção. 3ed, Rio de Janeiro: Zahar editores, 1973.

TORRES. S; GUERRA. A. Construção de um Instrumento de Avaliação para Anorexia Nervosa. Psicologia, saúde \& Drogas, v, 4, no 1, Lisboa, jul. 2003. 
HOW TO KNOW IF MY WORLD OF IDEAS IN PRACTICE WOULD WORK? fear of teaching in supervised internship in physical education

\begin{abstract}
The objective of this investigation was to recognize the implications of the fears experienced by future-teachers in their teaching. Three questionnaires were applied to 48 structured questions with future-teachers of Physical Education course UFPB. Using the techniques of content analysis of Bardin (2008), were mapped three themes: a) teaching practice and teaching b) difficulties of teaching and c) ways of overcoming fears. The fear appears as an essential emotion in action-future teachers. Because the feel, are urged to seek more knowledge to carry out their teaching practice and reflect on the intervention.
\end{abstract}

Keywords: Fear; Teach; Supervised Teaching.

Recebido em: maio/2013 Aprovado em: junho/2013 